\title{
15
}

\section{USES OF MAPPING}

\section{Methods of Investigation and Ways of Narrating Territory in Architectural Practice and Teaching}

\author{
Anne Portnoï
}

Mapping, understood here in the sense of a set of documents (maps, plans, diagrams, sections, models, photographs, sketches, accompanied by texts and captions, etc.), reflects the residential value of a territory's geography or reflects potential preexisting rules. These are all elements that need to be orchestrated in urban projects or interventions on a territorial level. ${ }^{1,2}$ Cartography's mission is also to narrate the story of the territory. This chapter attempts to distinguish several forms of storytelling that often overlap.

Using a case study from architectural practice and also examples from the educational framework, the author presents here a methodological distinction of three different uses of mapping by architects who are keen to connect architecture with territory and urbanization with greenspaces. This also corresponds to the three different reasons an architect wishes to create maps: to investigate, to transform, to be evocative. Examining these examples also gives us information about the possible sequencing of these investigation techniques and about the ways in which they can be used in context. Here, the author presents a first case study that describes a cartographic survey of the territory of Al Hoceima bay in Morocco carried out by landscape designers from the Agence Ter office. The author then analyzes several examples from her teaching experience at the Ecole Nationale Supérieure d'Architecture in Normandy and at the Ecole d'Architecture de la Ville et des Territoires in Paris-Est.

The first approach involves investigating and reconstructing. The story is used to uncover a series of events or actions with the aim of revealing a truth. Using these tools, the architect is able to illustrate and document the situation. An example is the work of Forensic Architecture, ${ }^{3}$ a British research group composed mostly of architects. The group uses tools normally used for the reconstruction of the urban environment to produce evidence in legal proceedings related to cases where human rights have been violated.

More commonly, architects use mapping with the aim of transforming a territory. The urban project unfolds over a period of time which is counted in decades and involves many different actors. Storytelling creates a shared interpretation of the territory. Establishing a common point of view of the territory is a way of guaranteeing its transformation. The production of a set of maps serves to give a single point of view and to gather the different 
actors of the project around a strong image, making a development strategy possible. This was the case with the map "Les Propriétés de Lucifer" (a map of "places belonging to Lucifer" identifying unpleasant areas) or the maps illustrating the concept of the "porous city," both developed in 2008 by Bernardo Secchi and Paola Vigano of Studio 08 \& 09, for their study of Greater Paris.

Finally, mapping may also have the sole purpose of touching the imagination, being evocative and creating an emotion, that is to say, representing a story in itself. The descriptive surveys of landscapes by James Corner and Alex Mac Lean ${ }^{4}$ stem from a desire for narrative. James Corner describes cartography as a creative activity and as a cultural project. These drawings or collages are produced with the aim of reformulating what is already established: cartography renews things again and again. ${ }^{5}$

\section{A Case Study: The Office Agence Ter at the Bay of Al Hoceima}

The study of Al Hoceima Bay by the Agence Ter office dates back to 2008, well before the 2016 protests that erupted in the Al Hoceima region. A French developer of medium size had the opportunity to acquire land along the coast that belonged to a member of the Moroccan royal family. Before putting the plots up for sale, the owner had a project for a large marina drawn up on this site. The French developer, who had long been developing projects while also taking environmental issues into account, wanted to cultivate 'sustainable tourism' in the area. He then turned to the Agence Ter to establish a diagnosis of the landscape, assessing the potential for building on the site, with regard to the environmental qualities of the land.

The developer did not give any documents to the Agence Ter to enable them to carry out this study. It was also impossible to obtain more information from the town planning authorities in the city of Al Hoceima. The study was thus based initially on the collection of data available on the Internet (climate, geology and geomorphology, human activities, hydrology of the Wadi or 'Oued' valleys, etc.). This first phase of the study revealed, on the one hand, the importance of the constraints linked to water and the risk of local overflows in the Wadi valleys and, on the other hand, the richness of the ecosystem, both on land and in the marine environment. Controlling water is a key issue in the region, which in 1981 led to the construction of a dam to help control and store run-off water, as well as a hydraulic network to distribute the water downstream.

The second phase of the study corresponded to a graphic transcription of the observations made of the geography on site, giving a more sensory appraisal and including details on the character of the different environments. The graphic renderings of these observations show in particular the visual perception of the horizons of the bay, as seen from the roads that go across it. The graphic interpretations distinguish the different environments created by landforms, hydrology, or human occupation. The hydraulic system is identified as being made up of two types: a network of pipes to irrigate the land and the canalization of the Wadi to control the riverbeds and flooding. Data collection and in situ observations were used to evaluate the program and allow the Agence Ter to assess the relevance of sustainable tourism. The quality of the unspoiled landscape of Al Hoceima Bay represents an asset, both for the development of agritourism and for that of the bay's horticultural economy (Figure 15.1).

The third phase involved a graphic survey that made it possible to establish an initial landscape diagnosis of the territory of the bay, including topography, water, plantations, 

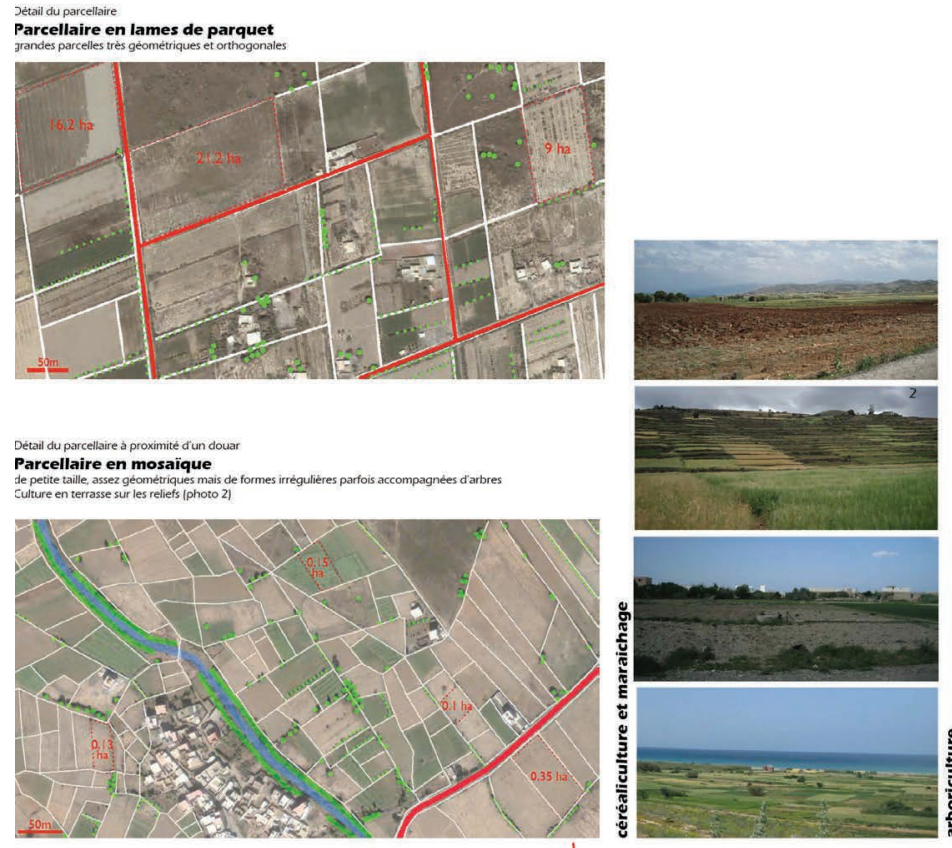

Agriculture et parcellaire

Agriculture: principal secteur de léconomie régionale, re-
groupe 6096 des actifs ceréaliculture (principalement agriculture en bour) : orge -arboriculture: amandier figuier, olviermaraichage/primeur (petites exploitations $<1$ ha parfois élevage (bovins, ovins, caprins) apiculture

Rendement des cultures toyjours modeste cer peu de mé canisation et dutilisation dengrais
Pratique agricole tributaire cu mode d'elevage principa pratiqué dans lexploitation (part importante des cultures (mun.alhoccimacity:com

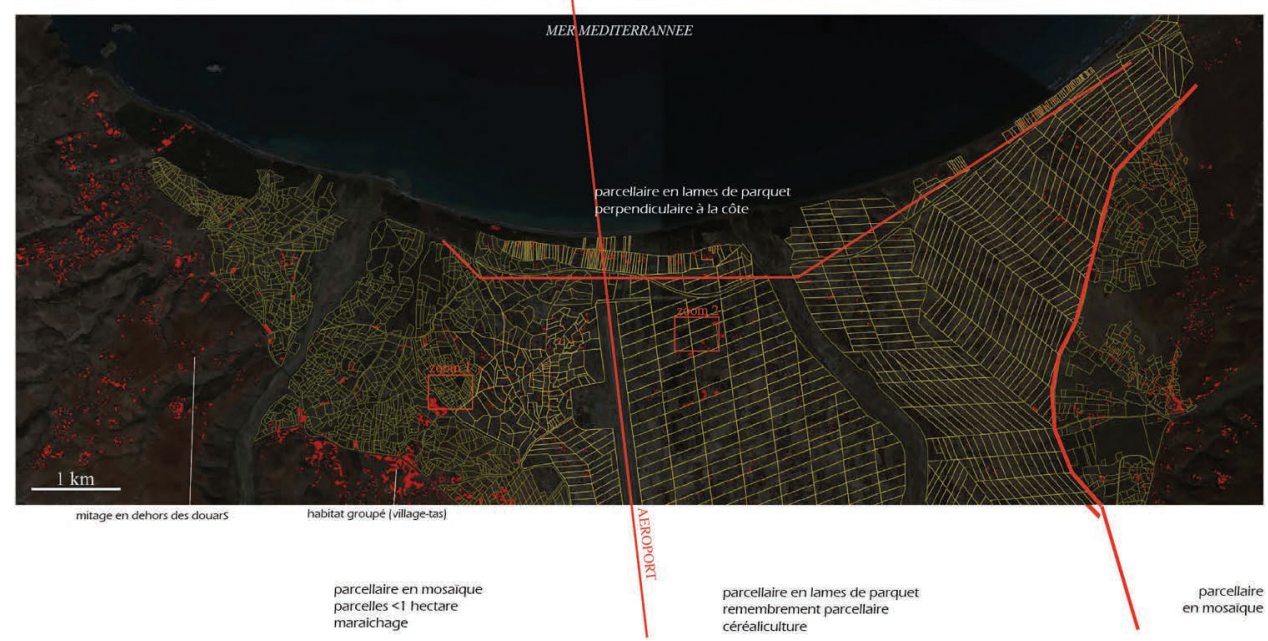

FIGURE 15.1 The graphic interpretations distinguish the different environments created by landforms, hydrology, or human occupation - Agence Ter 2008.

infrastructures, as well as the location of the buildings. The graphic survey then compared two different states of the bay: that described in a 1967 map from the archives of the Institut de géographie in Paris, which represents the area before the construction of the Abdelkrim al Khattabi dam, and the current situation as it appeared on the aerial photo at the time of the study. The purpose of this comparison was to take into account the changes in the area, by comparing the elements of the landscape (water, plantations, sand dunes, buildings, land consolidation). A cartographic analysis highlights the qualities of this landscape as well as its fragility and the fragility of the systems installed there. The most obvious signs of this 
instability are the retreat of the dune ridge, due to the canalization works on the Oued Nekôr as well as the significant increase in the number of dwellings built in an unplanned way along the main road. The hydraulic structures allow for the very rapid evacuation of rainwater toward the sea, resulting in a retreat of the coastline of up to 170 meters at the mouth of the Oued, where most of the land which was put up for sale is located. Taking this into account, it could therefore be said that, on a large part of this land, along the ridge of the dunes, building was not recommended. The study also revealed that coastal erosion was a known problem. The coast had also been partially wooded in order to stabilize the dune. The research using maps thus not only revealed that the line of the coast was retreating but also that the process was a known problem and that this had been concealed from the buyer. In the context of the project, these first steps of the cartographic study clearly form part of an investigation process, a search for truth, an intrigue (Figure 15.2).

The fourth phase of the study was no longer part of an investigation but became an element of urban design, through an interpretation of the landscape. The study carried out by Agence Ter, which was firstly an analysis of the land in search of the truth, then led to the creation of a set of recommendations, allowing the development of the landscape as an idea.
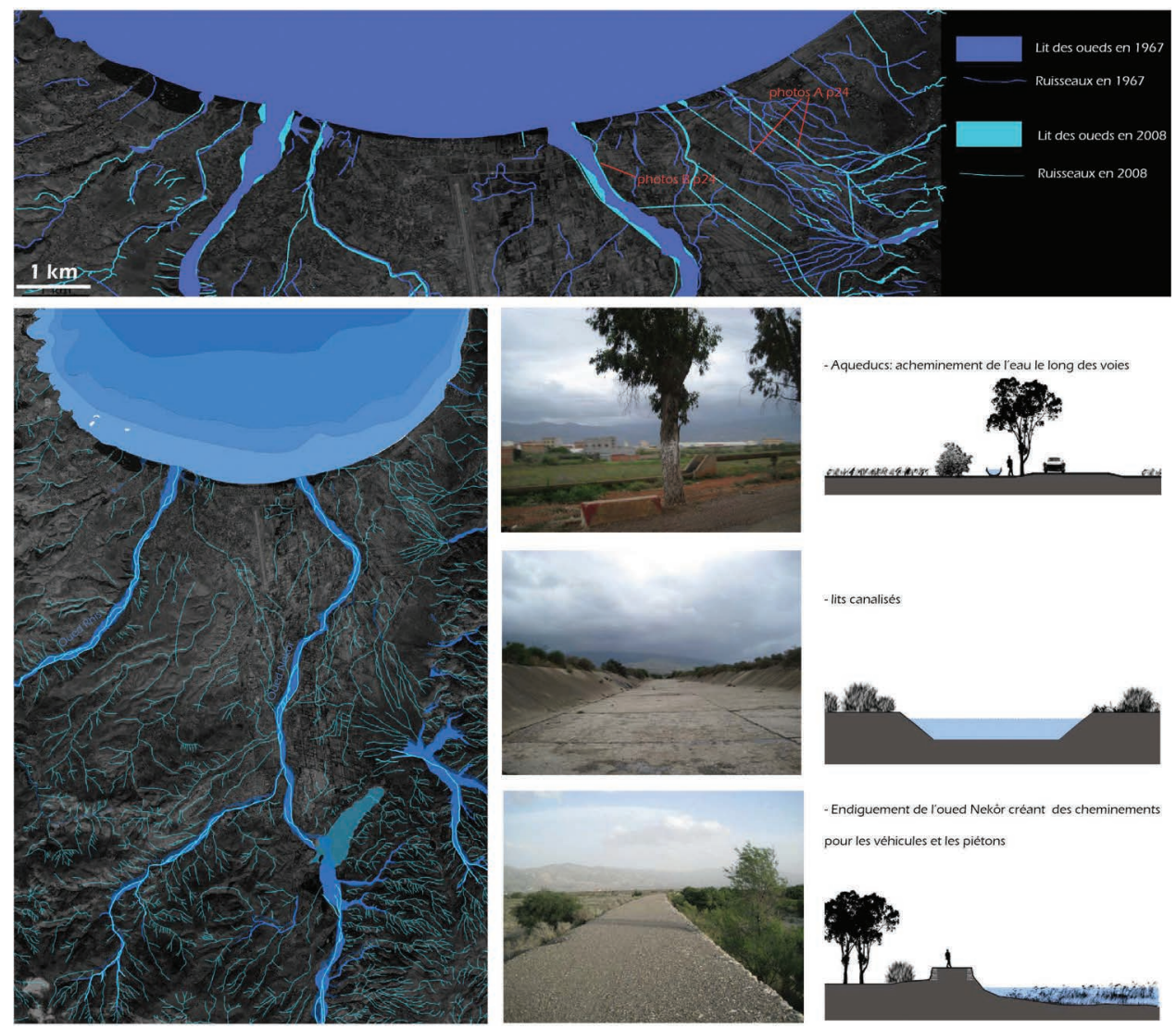

- lits canalisés
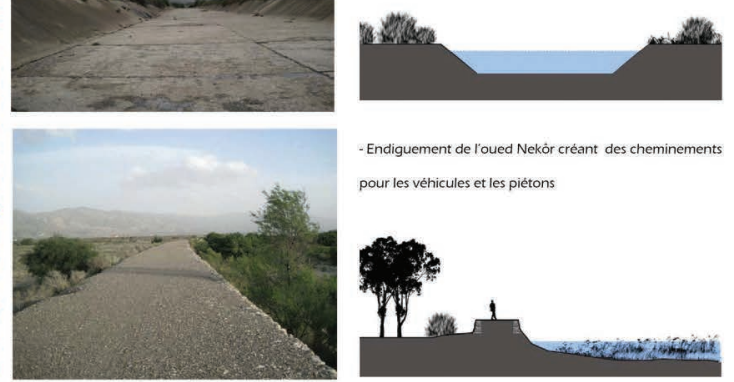

- Endiguement de l'oued Nekôr créant des cheminements pour les véhicules et les piétons

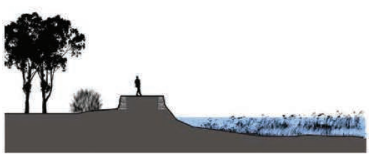

FIGURE 15.2 A cartographic analysis of the hydraulic structures and comparison of two different states of the Al Hoceima Bay - Agence Ter 2008. 
The way in which the territory was considered made it possible to make proposals for the use of different spaces and to design its transformation.

The complementary analysis carried out during the first steps showed that the elements that give structure to the landscape were not sufficiently established to allow for a development that would not threaten the balance and the coherence of the landscape of the bay. These elements needed to be reinforced in order to allow for an intelligent form of development, through the idea of the landscape itself. The aim was to define guidelines for the sustainable development of the bay. Following their diagnosis, Agence Ter was able to make recommendations and to define the main principles for intervening in the territory, at different scales. This was by no means a feasibility study, but rather a hypothesis for the possible reforestation of the coast, planting a $400 \mathrm{~m}$ wide strip along the dune ridge, and including the diversification of the tree species present. This wooded zone has several functions: stabilizing the dune, providing shelter from the wind, and creating a horizon. The scenery of the coastline is laid out in relation to the main road which acts as a viewpoint. The buildings are constructed in the wood behind, and the first $100 \mathrm{~m}$ of woodland are left free of construction. At the back of the dune, in the forest, the developed area is protected from the winds, is better oriented and shaded, and takes advantage of the coolness of the humid zones where part of the wastewater is treated, allowing for the overflow of the Wadi and enriching biodiversity. Finally, these main principles allow an appropriate building perimeter to be calculated for the available land. These recommendations are also based on a more comprehensive vision of the future of the bay and its possible economic development. The study suggests the creation of an agricultural park and the development of a horticultural economy, and a plant nursery as a response to the demand created by large urban projects around the Mediterranean, in Morocco and in Europe. The possible narrative for this territory was thus developed from both a spatial and economic perspective.

\section{Storytelling in the Teaching of Architecture}

In the case of teaching exercises, the different survey methods and cartography registers used as an approach by Agence Ter need to be simplified in order to facilitate the acquisition of knowledge by the students. The three different storytelling formats that can be applied when mapping a territory - investigating, transforming, being evocative - are used differently depending on the class year and the framework in which they are being taught. The objectives and expected results are not the same for a project workshop or for a tutorial on urban or territorial analysis.

At the ENSA Normandie architecture school, as part of the 'project' workshop, there is a tutorial in urban analysis that introduces first-year students to various tools for representing space and the urban landscape. Students map a neighborhood before working on a plot. The way in which the different elements are represented are not dictated to the students; on the other hand, the application of a certain number of tools (perspectives in sequence, surveys of urban fragments and situations, close-ups, sections at different scales) introduces the students to the notion of what is 'already there'. This allows them to use their observations when defining the themes for the projects that they will subsequently develop (Figure 15.3). 

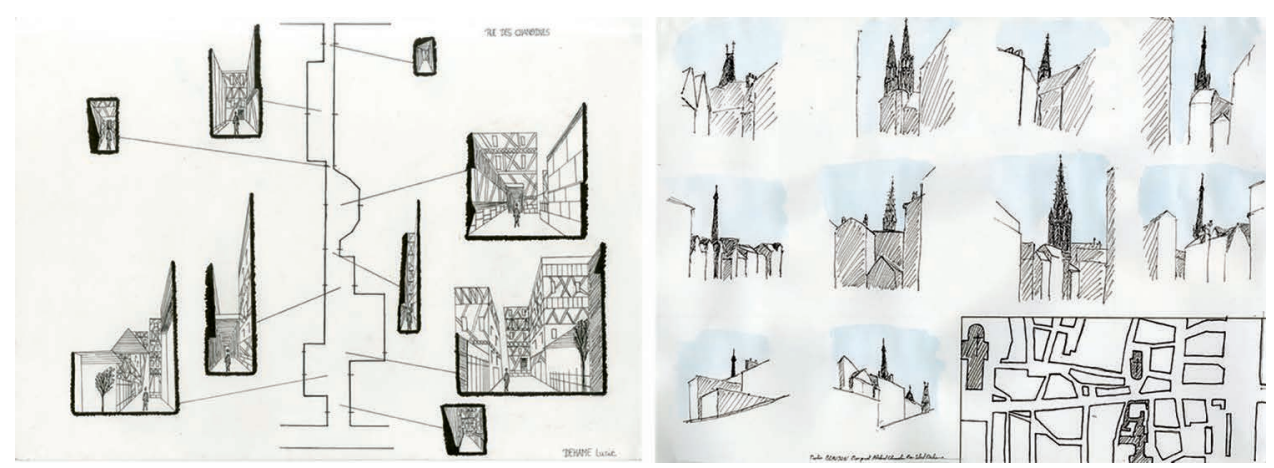

FIGURE 15.3 ENSAN, first-year design studio (2017-2018). L. Engrand and A. Portnoï are associate professors, and the students who participated in the design project include C. Abelard, M. Beaujon, K. Ben Tabed, A. Bocquet, E. Chasselin, and L. Dehame.

The work given in the third year of the undergraduate degree course combines two types of spatial register. The student learns to 'read' a territory, to understand its economic and social issues and to develop exploratory work on the design of public space and residential fabrics. Over a period of 5 weeks, the students develop a cartographic survey of the territory, with the aim of raising questions that will be answered by the project. This is to introduce students to the idea of making a diagnosis of a territory and the use of mapping a site in order to define a set of questions. The students have to use a set type of analysis grid. This grid is established in such a way as to highlight the structure of the territory and the landscape as well as the residential value of the geography, that is to say the relationships between these geographical characteristics and the urban history, major routes, location of important facilities, use values, qualities in terms of space and landscape of public spaces, distant views and perceptions, and different urban forms of the territory. Vacant or undervalued spaces, margins, and fractures in morphology are also highlighted. This cartographic work is used secondly to help identify issues and a corresponding development strategy as well as to define the most relevant sites for projects with regard to these questions. To exemplify the different possibilities, different scenarios for transformation are verified across the architectural scale. The last weeks of the semester are devoted to reformulating these ideas and looking at the ways in which the subject can be most suitably represented (Figure 15.4).

In the case of the undergraduate degree course, the different rules of visual representation and the use of a 'grid' for the interpretation of a territory are at the heart of what the students learn. The diagnosis approach introduces students to the use of inquiry - both as a means of searching for truth and as a means of transformation. While the undergraduate students study mapping in order to be capable of giving a coherent and personal reading of a territory, this method is mainly developed in the postgraduate/master's course, where students are required to identify issues and relate the story of a town or city. In the master's course at the ENSA Normandie School, the workshop that belongs to the module "architecture, towns and territories" focuses on the Seine valley and the medium-sized towns and urbanized countryside in the Normandy region. Following the example of the Agence Ter approach, the project workshop aims to design projects that will be 'in equilibrium' with their 

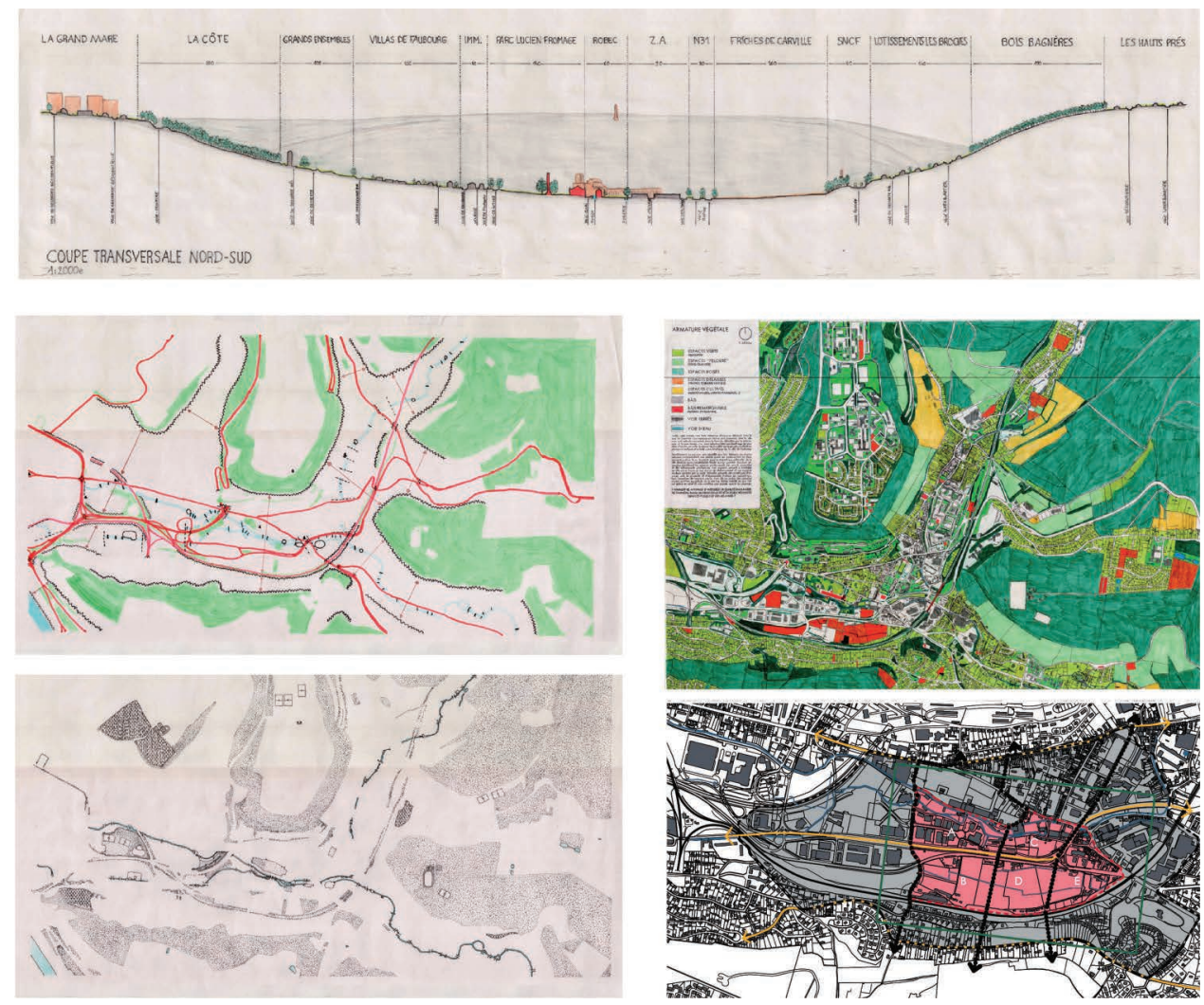

FIGURE 15.4 ENSAN, third-year design studio (2016-2017). J. M. Bichat and A. Portnoï are associate professors, and the students who participated in the project include Ch. Arzur, L. Daunora, A. Salaün, J. Simonnet, and M. Yahi.

context, using the specific constraints or potentials of these spaces. The questions raised relate not only to how growth occurs in the urban situations studied but also to changing modes of inhabiting spaces, mobility, and services provided in these territories (Figure 15.5).

Particular attention is paid to preserving and enhancing the exceptional geography of the sites studied, in terms of natural resources and heritage, in a territory that is in parts affected by climate change. The exercise takes into account environmental issues and the contemporary importance of risk, focusing in particular on the renewal of non-urbanized spaces, and on questions relating to public spaces that are in part shaped by water management.

The semester is organized in four steps: surveying and understanding the territory together with creating a synthesis of existing studies and documents; analysis considered as knowledge and definition of a transformation problem; proposing a scenario and different tests at the architectural scale; and the formalization and representation of a story. Thus, teaching centers on the analytical description (drawings, interviews, governance, and history) of the territory being studied. Cartographic tools are used for 'reading', describing, and conceptualizing a contemporary territory. These tools also constitute a body of knowledge enabling the students to forge an individual opinion on architecture and the organization of space. Students are asked to combine analytical knowledge with historical and 

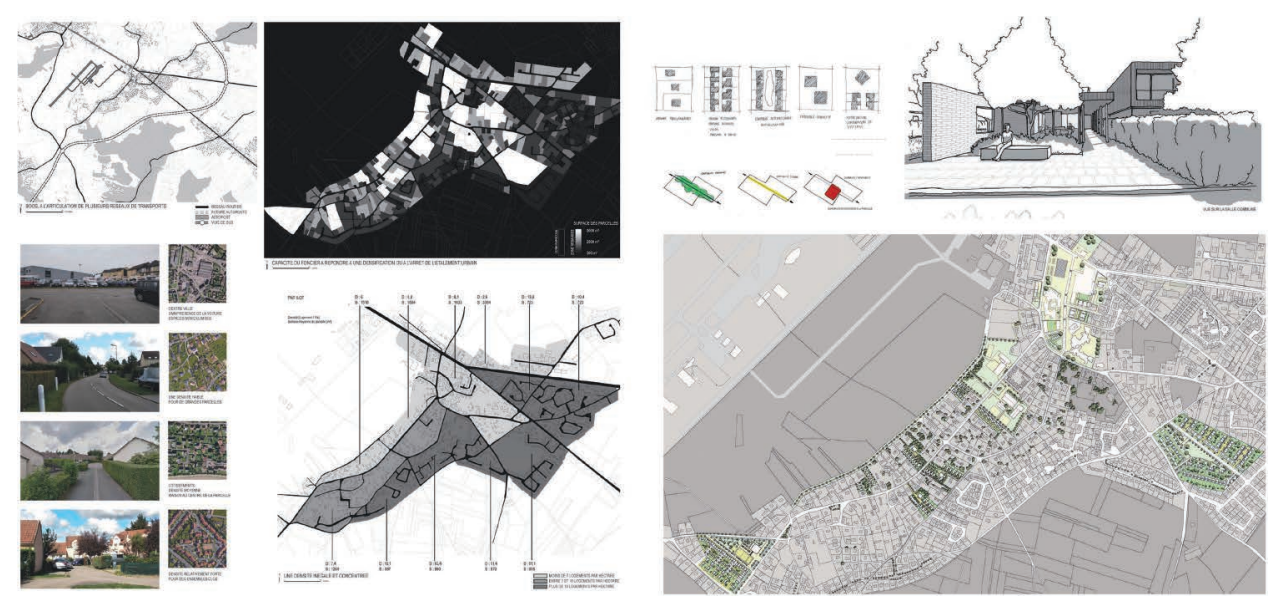

FIGURE 15.5 ENSAN, fourth-year design studio (2018-2019). J. M. Bichat and A. Portnoï are associate professors, and the students who participated in the project include $M$. Couchaux, B. Bouchez, C. Sarrazin, and V. Lefevre.

theoretical knowledge in order to develop spatialized projects that relate to the questions asked. Although in the third year the teaching is based on the study of densification and residential projects in different forms, in the master's degree, the course content is not defined by the professors but instead by the territory itself. The work is completed by the creation of a scenario and the building up of a story.

Apart from allowing students to learn in a progressive way about the tools for territorial diagnosis, the format of the exercise also changes the method of narration. When studying 'projects', students are required to investigate, transform, and be evocative. However, in the "architecture, towns and territories" module, in the case of the tutorial for second-year students called "telling the story of the territory" devoted to mapping, it is a question of exploring this tool in its narrative form. This analytical exercise is disconnected and dissociated from the issue of site transformation. The students are encouraged to understand a certain number of tools and to tell a story about the territory with no other objective than that of giving a certain perception of it or of stating their individual point of view regarding the territory in question. The story told is thus clearly associated with an evocatory function, a means of developing the imagination. The organization of the course in two-week phases corresponds to the themes used: understanding the site, mapping elements of the landscape, structure and perception, mapping public space, mapping the urban fabric and making an inventory of urban forms, and finally mapping in order to illustrate a point of view, a story. Each group of students are free to choose and amplify a particular point of view of the territory. The question of nature in the city is a recurring theme, whether, for example, through the relationship between built and natural elements in different urban forms or the role of infrastructure as a limit or a vector for biodiversity (Figure 15.6).

Whether it is linked to a development strategy or not, the story told for the territory is thus destined to be shared with a set of different actors in the long term. The workshop from the master's course allows for partnerships with local authorities and other stakeholders from the territory. From a pedagogical point of view, placing students in the position where they 


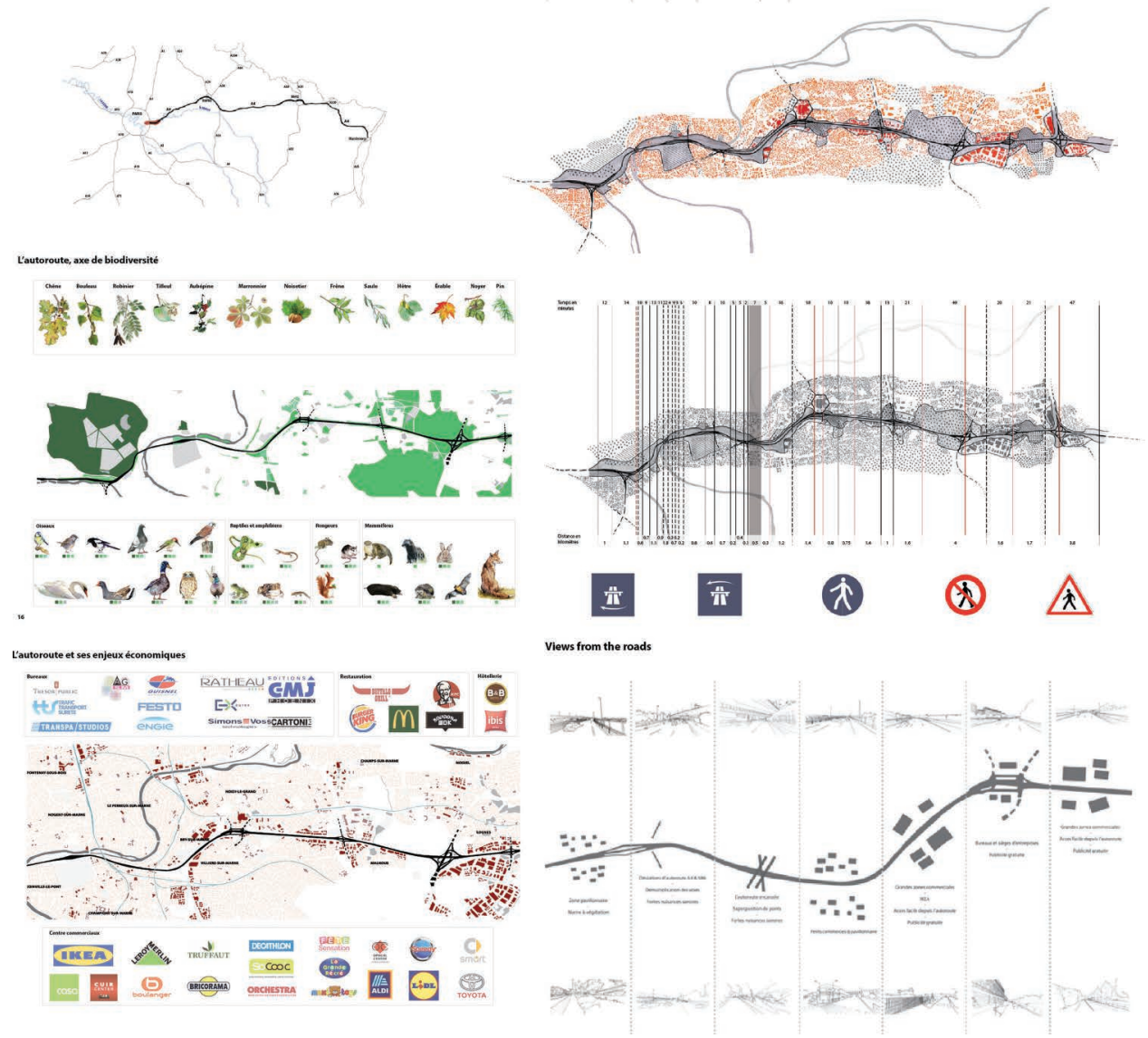

FIGURE 15.6 EAVT-Paris-Est, second-year tutorial class (2018-2019). A. Delchet and A. Portnoï are associate professors, and the students who participated in the project include C. Felix, L. Hamon, A. Salaün, and A. Michel.

can bring together various different interlocutors, visions, and dimensions is an essential teaching approach, giving them a better understanding of a territory and how it is managed. Conversely, the educational framework also transforms the actors' relationships with their territory (different especially from the relationship the contracting authority has) and thus their frame of mind and their receptivity to a territorial narrative. The resilience of the territories is enriched by the fact that these actors are confronted with other perspectives, enriching their vision beyond that of actions and responsibilities. The educational framework allows for the development of many differentiated and varied interpretations, that can often be unexpected, thus increasing the physical knowledge of a territory. The educational system, in its own way, thus acts positively, as a means of increasing the resilience of the territories. 


\section{Notes}

1 This article is an extract from a conference given as part of the Erasmus+ Programme, ArchéA "Spaces of the City. City of Spaces." Rheinisch-Westfälische Technische Hochschule, Aachen. September 19, 2019.

2 Lootsma, B. 2003. Synthétic Regionalization: The Dutch Landscape toward a Second Modernity. In J. Corner, Recovering Landscape. New York: Princeton Architectural Press.

3 https://forensic-architecture.org

4 Corner, J. and A. S. MacLean. 2000. Taking Measures across the American Landscape. New Haven, CT: Yale University Press.

5 Cosgrove, D. E. 2002. Mappings. London: Reaktion.

6 Second-year students from the undergraduate degree coursework 6 hours per week in a group of 25 students with two professors, an architect, and a graphic designer.

\section{Bibliography}

Corner, J. and A. S. MacLean. 2000. Taking Measures across the American Landscape. New Haven, CT: Yale University Press.

Cosgrove, D. E. 2002. Mappings. London: Reaktion.

Lootsma, B. 2003. Synthétic Regionalization: The Dutch Landscape toward a Second Modernity. In J. Corner (ed.), Recovering Landscape. New York: Princeton Architectural Press, pp. 251-274. 